\title{
An endodontic practice profile amongst general dental practitioners in Kathmandu: A questionnaire survey
}

\author{
Shrestha $\mathrm{D}^{1}$, Dahal $\mathrm{M}^{2}$, Karki $\mathrm{S}^{3}$ \\ ${ }^{1}$ Lecturer, Department of Conservative Dentistry and Endodontics, Kathmandu University School of \\ Medical Sciences \\ ${ }^{2}$ Lecturer, Department of Conservative Dentistry and Endodontics, KIST Medical College \\ ${ }^{3}$ Dental Surgeon, Department of Conservative Dentistry and Endodontics, Kathmandu University School \\ of Medical Sciences
}

\section{ABSTRACT \\ Objective}

To investigate the endodontic practice profile of general dental practitioners.

To explore the materials and methods employed by them in Kathmandu valley.

To compare these findings with well acknowledged international academic standards.

\section{Methods}

Questionnaires with 18closed-ended questions were distributed among randomly chosen 120 general dental practitioners of Kathmandu, working in various government or private hospital or clinics.The data were collected and descriptive statistical analysis was done.

\section{Results}

Out of 120 questionnaires, only 110 that were completely filled were included in the study .Most general dental practitioners (97\%) regularly did multi-rooted root canal treatments and followed multivisit root canal treatment.. Radiograph with instrument in canal was used by $80 \%$ of general dental practitioners to determine the working length while only $36 \%$ used electronic apex locator which is considered to be more reliable. Half of them (57\%) used nickel-titanium files for cleaning and shaping but only $23 \%$ used crown down technique. Sodium hypochlorite and calcium hydroxide was the most popular irrigation solution and intra-canal medicament respectively. Majority of general dental practitioners (91\%) used lateral compaction technique for root canal obturation. Sixty three percent used zinc oxide eugenol as root canal sealer and $46 \%$ used endomethasone. They seem to overuse antibiotics in cases requiring endodontic therapy. Only $48 \%$ used autoclave for sterilization of endodontic files while $86 \%$ never used rubber dam. Eight three percent of them felt the need of further endodontic training and $42 \%$ of them preferred post-graduate dental program.

\section{Conclusion}

This study shows that the standard guidelines and new technologies for endodontic treatments are not implemented by many general dental practitioners of Kathmandu and require further endodontic trainings.

\section{KeyWords: endodontic treatment, general dental practitioner, questionnaire survey.}


Journal of College of Medical Sciences-Nepal, 2013, Vol-9, No-4,

\section{INTRODUCTION}

With the introduction of new materials, devices and techniques, quality of endodontic treatment has increased leading to higher endodontic success rate. With the development of these technologies, many teeth with guarded prognosis that used to be extracted in the past can be salvaged by surgical or non-surgical endodontic treatment.

Previous questionnaire surveys done in developed and developing countries like United Kingdom (UK), Hong Kong (HK), North Jordan, Belgium, India and Sudan has shown that the most general dental practitioners (GDPs) and endodontists practice what they have been taught in their dental school and fail to apply new technologies and materials in their daily practice, while others practiced the technologies with no scientific basis. ${ }^{1-6}$ There are no study done in this field in Nepal and hence it is a necessity to conduct such survey to gain knowledge regarding endodontic practice profile, implementation of new technologies and identify the problems in implementation of these methods and materials and need for organization of further endodontic continued dental education programs.

\section{METHODS}

For this cross-sectional study, the questionnaire used by Chan et al ${ }^{2}$ was taken and a pilot study was conducted for reliability, validity, refinement and clarity. ${ }^{7}$ After the pilot study, 18 close-ended questions were chosen for the study. GDPs working in different government hospitals and private hospitals and clinics of Kathmandu valley were randomly chosen to take part in this survey. The study was conducted between April 2013 and June 2013. Only those who were ready to volunteer $(n=120)$ were distributed questionnaires with a cover letter with information about principal investigator, purpose and confidentiality. The data were collected and descriptive statistical analysis was done using statistical package for social sciences (SPSS) (version 16.0; SPSS Inc, Chicago, IL).

\section{RESULTS}

Out of 120 distributed questionnaires, 110 were returned with completely filled questionnaire and included for data analysis. The results of the questionnaire are shown in table 1 (16 questions), figure 1 and 2. The GDPs regularly treated more cases of multi-rooted endodontic cases (97\%), followed by single-rooted $(79 \%)$ and retreatment cases $(70 \%)$. The number of endodontic treatment performed per week were $0-5$ teeth by 40 dentists(36\%), while others(26\%) did 6-10, 22\% did 11-15 teeth and only $14.5 \%$ of them performed more than 15 cases per week. Rubber dam was never used by 95 (86\%), occasionally by $13(9 \%)$ and always by $2(1.8 \%)$ GDPs. Most of them preferred doing multiple visit endodontic therapy for vital and non-vital single rooted and multirooted teeth (Figure 1). Calcium hydroxide (90\%) and formocresol (28\%) were the most commonly used intra-canal medicament.

For working length determination, radiograph with instrument in the canal was used by $88(80 \%)$ dentists followed by apex locator by $40(36 \%)$ and pre-operative radiograph by 37 (33\%) of them. Regarding frequency of radiographs taken during various steps of endodontic treatment is shown in figure 2 . Out of them, $86 \%$ and $91 \%$ of them always took pre-operative and working length radiograph respectively. Cone fit radiograph and postobturation radiograph were always taken by $68.18 \%$ and $54.54 \%$ dentists respectively. The frequency of taking follow up radiographs was comparatively less with only $20.9 \%$ GDPs always taking it. 
An Endodontic Practice Profile Amongst General Dental Practitioners..

Stainless steel, nickel titanium hand files and rotary nickel titanium files were used by $88 \%, 57 \%$ and $12 \%$ of the participants respectively. The most popular root canal instrumentation technique was step back with $90 \%$ of them using this technique while only $23 \%$ used crown down technique. The most commonly used irrigation solution were normal saline $(91 \%)$ and sodium hypochlorite (91\%) followed by hydrogen peroxide $(46 \%)$.

Majority of GDPs (91\%) used lateral compaction technique for root canal obturation. Single cone and warm compaction technique were followed by $11 \%$ and $5.45 \%$ of dentists respectively. More than half of them (63\%) used zinc oxide eugenol as root canal sealer, $46 \%$ used endomethasone, $11 \%$ epoxy-resin and $6.36 \%$ used calcium hydroxide based sealer.

Regarding use of antibiotics, it was prescribed for patients with swelling by $82 \%$, for presence of sinus tract by $65 \%$, for symptomatic by $45 \%$ and for tooth tender to percussion by $27 \%$ of the participants.

\section{Figure legends:}

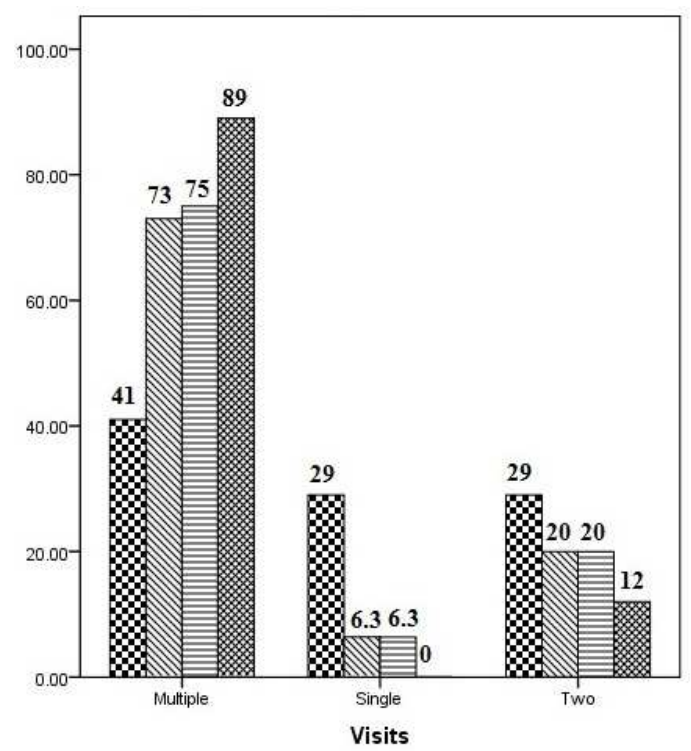

Figure1. Diagrammatic representation of total number of visits required for single-rooted vital (SRV), single-rooted non-vital (SRNV), multirooted vital (MRV) and multi-rooted non-vital teeth (MRNV) in percentage.
Almost all of them (88\%), prescribed broad spectrum penicillin, followed by metronidazole (70\%), amoxicillin+clavulanic acid (28\%), tetracycline $(2.7 \%)$ andfluoroquinolone $(0.9 \%)$. Half of the GDPs used glass bead sterilization $(50 \%)$ and autoclave $(48 \%)$ for sterilization of endodontic files, $20 \%$ used chemical sterilization while only 1 disposed after single use. Most of the participants disposed the files after seeing signs of distortion $(76 \%)$ or when files became blunt $(58 \%)$. The files were disposed after single use by 1 , after 3 times by 1, 4-5 times by 2 and 6 times by 1 participant.

Out of 110dental graduates, $83 \%$ thought they required further training in endodontics. The preferred further training was continued dental education (CDE) with hands on program (50.9\%), followed by post-graduate program $(42 \%)$, parttime structured program (24\%) and CDE-lectures (11\%).

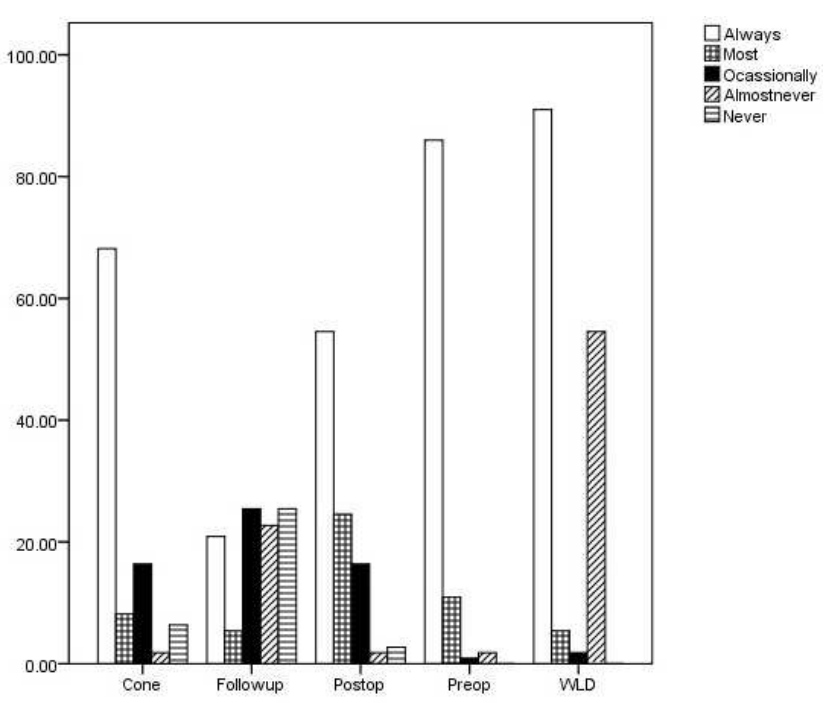

Figure 2. Diagrammatic representation of frequency of radiographs taken for pre-operative (preop), working length determination (WLD), cone fit (cone), post-operative (postop), and follow up (followup) in percentage. 
Journal of College of Medical Sciences-Nepal, 2013, Vol-9, No-4,

able 1. Result of the questionnaire (only 16 out of 18 questions are included)

\section{Questions}

1. Do you regularly treat
a. Single rooted endodontic cases
b. Multi-rooted endodontic cases
c. Retreatment cases

No. ofs

respondent

87

107

77
Respondents (in percentage)

79

97.27

70

2. In your endodontic treatment, do you use rubber dam?
a. Always
2
1.81
b. Occasionally
13
11.8
c. Never
95
86.36

3. On the average, how many root canal therapies do you perform per week?
a. 0-5 teeth
b. 6-10 teeth
c. 11-15 teeth
25
22.72
d. 16-20 teeth
11
10
e. 21 teeth or above
5
4.54

4. If more than one visit, what dressing/ medication do you use?
a. Calcium hydroxide
100
90.9
b. Formocresol
c. lodoform
d. Formaldehyde
e. Antibiotic paste
f. Metapex
1.81
g. Septomix
0.9
h. Fresh cotton

5. Method of working length determination
a. Apex locator
b. Pre-operative radiograph
c. Radiograph with instrument in the canal
d. Master cone
e. Tactile sensation
f. Paper point

6. To prepare canals, do you routinely use
a. Stainless steel hand files
b. Nickel-titanium hand files
c. Rotary nickel-titanium hand files 
An Endodontic Practice Profile Amongst General Dental Practitioners..

7. Method of root canal instrumentation
a. Step back technique
b. Crown down technique
c. Push and pull

8. For irrigation of root canals, which irrigation solution would you use?
a. Sodium hypochlorite
b. Chlorhexidine
c. Hydrogen peroxide
d. Ethylene diamine tetra acetate (EDTA)
e. Normal saline

9. What type of obturation technique do you routinely use?
a. Lateral compaction
101
91.81
b. Warm compaction
c. Single cone

10. Which root canal sealer do you use during root canal obturation?
a. Zinc-oxide eugenol
b. Endomethasone
c. Epoxy-resin
d. Calcium hydroxide

11. Do you prescribe antibiotics for patients undergoing endodontic therapy?
a. If symptom or pain is present
b. If sinus tract is present
c. If swelling is present
d. If tooth is tender to percussion
24.54

12. Which antibiotic would you prescribe?
a. Amoxicillin + clavulanic acid
b. Broad Spectrum penicillin ( eg. Amoxicillin, ampicillin)
88.18
c. Tetracycline
d. Metronidazole
e. Fluroquinolone
f. Macrolides

13. How do you sterilize your endodontic files?
a. Glass bead sterilization
b. Autoclave
c. Chemical Sterilization
d. Dispose after single use 
Journal of College of Medical Sciences-Nepal, 2013, Vol-9, No-4,

14. When do you dispose your endodontic files?
a. After single use
1
0.9
b. After 3 times of use
1
0.9
c. After 4-5 times of use
1
0.9
d. after 6 times of use
1
0.9
e. The file becomes blunt (decreased cutting efficiency)
58.18
f. See signs of distortion
64
76.36

15. Do you think you need further endodontic training after graduation?
a. Yes
92
83.63
b. No
18
16.36

16.If yes, would you prefer
a. Post-graduate program (eg. MDS, MSc)
47
42.72
b. Part-time structured program (eg. Post graduate diploma)
27
24.54
c. Continuing education courses - lectures
13
11.81
d. Continuing education courses- hands on
56
50.9

\section{DISCUSSION}

This study, which included the GDPs of Kathmandu valley, investigated the endodontic practice profile. It showed that endodontic treatment for single rooted and multi-rooted including retreatment cases are frequently carried out by GDPs of Kathmandu. Most of the GDPs (86\%) never used rubber dam which was similar among those of Hong Kong,Belgium and Sudan. ${ }^{2,4,6}$ This may be due to cost, skill and time factors and may influence the choice of irrigant and negatively affect treatment outcome. ${ }^{8}$ Rubber dam application for endodontic treatment is mandatory for patient protection and isolation. The GDPs may even face medico-legal problem for negligence if any endodontic instrument is aspirated accidentally by the patient.

Most of the dentists practiced more than two visit endodontics for single-rooted, multiple-rooted, vital and non-vital cases. Single-visit root canal treatment offers several advantages such as a reduced flare-up rate, good patient acceptance, less time-consuming, resulting in less cost for the patient, potentially more profit for the dentist, less painful and less traumatic than multi-visit treatment. ${ }^{9,10}$ On the other hand, bacterial eradication cannot be predictably maximized without intracanal medicament between appointments; thus, the potential for healing may be compromised. ${ }^{11}$ However, no detectable difference was found in the effectiveness of root canal treatment in terms of radiologic success between single and multiple visits. ${ }^{12}$ The actual preference for multiple visits must be because of practice management, operator convenience, complexity of the case, weeping canal or simply a habit. $^{5}$

For intracanal medicament, calcium hydroxide usage was the most popular followed by formocresol, which was similar to that practiced by dentists in $\mathrm{HK}$ and endodontists of India. ${ }^{2,5}$ Calcium hydroxide has been determined as suitable for use as an intracanal medicament as it is stable for long periods, harmless to the body, and 
An Endodontic Practice Profile Amongst General Dental Practitioners.

bactericidal in a limited area. It also induces hard tissue formation and is effective for stopping inflammatory exudates. Besides, intracanal dressing is also for a blockade against coronal leakage from the gap between filling materials and cavity wall. On the other hand, formocresolhas a tissue fixative property and also is distributed to the whole body from the root apex and so might induce various harmful effects including allergies. Furthermore, as these medicaments are potent carcinogenic agents, there is no indication for these chemicals in modern endodontic treatment. ${ }^{13}$

Most of the dental surgeons (80\%) used radiograph with instrument in the canal to determine the working length while others used apex locator (36\%), pre-operative radiograph $(33 \%)$, cone-fit radiograph (20\%), tactile sensation (18\%), and paper point method (3.6\%). Periapical radiographs are important in endodontics for diagnosis, determine the number, location, shape, size, and direction of roots and root canals, estimate and confirm the length of root canals before instrumentation, localize hard-to-find, or disclose unsuspected, pulp canals by examining the position of an instrument within the root, aid in locating a pulp that is markedly calcified and/or receded, determine the relative position of structures in the facial-lingual dimension, confirm the position and adaptation of the primary filling point and aid in the evaluation of the final root canal filling. ${ }^{14}$ However, conventional radiographs; which include the compression of the complex three-dimensional anatomy into a two-dimensional shadowgraph, anatomical noise and geometric distortion, it cannot consistently reveal the true nature and location of apical foramen. ${ }^{15}$ The apical foramen is located laterally in $78 \%$ to $93 \%$ of the cases. ${ }^{16}$ Therefore, there is need of use of electronic apex locator to determine the apical foramen. The correct use of an apex locator alone could prevent the need for further diagnostic radiographs for determination of working length. This method can be useful in patients who need not to be exposed to repeated radiation because of mental, medical or oral conditions. ${ }^{17}$ Moreover, electronic apex locators areparticularly useful when the apical portion of the canalis obscured by anatomic structures, such as impactedteeth, tori, the zygomatic arch, excessive bone density,overlapping roots or shallow palatal vaults. ${ }^{18}$

Stainless steel hand files were used by $88 \%$ of the GDPs while only $57 \%$ and $12 \%$ used hand and rotary $\mathrm{Ni}-\mathrm{Ti}$ files respectively. The primary objectives of cleaning and shaping the root canal system is to remove the infected soft and hard tissues and give disinfecting irrigants access to the apical canal space while preserving as much tooth structure as possible. Nickel-titanium files have the advantage of super-elasticity, causing lesser canal aberrations. ${ }^{19}$ However, they cannot solve every clinical situation and the use of hand stainless steel is inevitable.A crown-down approach provides certain advantages including early organic debris removal, the creation of a large reservoir for irrigating solutions, a straighter access to the apical region of curved canals, and greater precision with regard to the exact working length and apical size. ${ }^{20}$ Only $23 \%$ of the GDPs used crown-down technique while $90 \%$ still followed step-back technique.

Proportionally large areas of the main root-canal wall remain untouched by the instruments, emphasizing the importance of chemical means of cleaning and disinfecting all areas of the root canal. ${ }^{21}$ Sodium hypochlorite, the most widely used endodontic irrigant, dissolves the organic material and possesses a broad spectrum antimicrobial activity against endodontic microorganisms and 
Journal of College of Medical Sciences-Nepal, 2013, Vol-9, No-4,

biofilm, including microbiota difficult to eradicate from root canals. ${ }^{22}$ Sodium hypochlorite and normal saline was used by equal number of GDPs (91\%). Hydrogen peroxide, chlorhexidine and EDTA were used by $46 \%, 17 \%$ and $11 \%$ respectively. The result of this study was similar to the questionnaire survey done by Reetuet al on endodontic irrigation trends among the GDPs of Nepal. ${ }^{23}$ Once more, it should be emphasized that a single irrigant may not have all the properties of an ideal root canal irrigant. Optimal irrigation is based on the combined use of two or several irrigating solutions, in a specific sequence, to predictably obtain the goals of safe and effective irrigation. ${ }^{24}$

Lateral compaction technique was more popular among GDPs of Kathmandu. Eleven percent of them used single cone technique and $5.45 \%$ used warm compaction technique. Warm compaction technique fills the root canal system and flows into the irregularities, fins,isthmus and lateral canals. However, long term clinical success and obturation quality was similar to that of lateral compaction. ${ }^{25}$ Root canal sealer is necessary to seal the space between the dentinal wall and the obturating core interface, fill the voids and irregularities in the root canal, lateral and accessory canals and provide a fluid impervious seal. ${ }^{26}$ The preferred root canal sealer was zinc-oxide eugenol,which was used by $63 \%$ of GDPs. Others used endomethasone (46\%), calcium hydroxide and epoxy-resin (11\%). In a biocompatibility study, the best result was obtained with root canal filling with Endométhasone short of the apical foramen but a chronic inflammatory infiltrate was present in all specimens. ${ }^{27}$ Endomethsone contains paraformaldehyde and sealers containing paraformaldehyde are contraindicated in endodontic treatment. These sealers are not approved by the U.S. Food and Drug Administration and are unacceptable under any circumstances in clinical treatment because of the severe and permanent toxic effects on peri-radicular tissues. ${ }^{27}$ Such sealer can even cause allergy, angioedema or anaphylactic shock. ${ }^{28,29}$ Root canals sealers that bond to the root dentin like resin based sealer has gained wide popularity in endodontics. Studies using epoxy-resin and methacrylate resin based sealers have shown to be better, no significant difference or worse than other sealers in various comparative studies. ${ }^{30}$ Manufacturers claim that the methacrylate resin based sealers (eg. Resilon, Epiphany) bond to both the root dentin and Resilon core to form a monoblock to strengthen the tooth structure. ${ }^{31}$ However, they also have their limitations like difficulty of applying bonding agents in the apical one third of the canal, extrusion of allergenic unpolymerized resin, High C-factor inside the root canal system, decreased polymerization due to interaction with residual irrigating solutions or tissue remnants. ${ }^{32}$

Eighty two percent of the dentists used antibiotics in case of swelling, more than half used it in cases with sinus tract. Antibiotics were used in symptomatic cases with pain by $45 \%$ and by $27 \%$ in cases where the tooth was tender on percussion. Eighty eight of them used broad spectrum penicillin, $70 \%$ used metronidazole, $28 \%$ used amoxicillin+clavulanic acid and $2.7 \%$ used tetracycline.Due to the potential risk of adverse effects following systemic application, and the ineffectiveness of systemic antibiotics in necrotic pulpless teeth and the peri-radicular tissues, the local application of antibiotics may be a more effective mode for delivery in endodontics. ${ }^{30}$ This study shows that GDPs have been overusing the 
An Endodontic Practice Profile Amongst General Dental Practitioners.

systemic antibiotics and patients are at high risk of developing resistance to antibiotics.

In this study, more GDPs (50\%) used glass bead to sterilization, others used autoclave $(48 \%)$ and chemical sterilization (20\%). Since $58 \%$ and $76 \%$ of the GDPs disposed the files after they became blunt and saw signs of distortion respectively, reuse of endodontic files after sterilization is high. The complex miniature architecture of endodontic files makes pre-cleaning and sterilization difficult. Devising a sterilization protocol for endodontic files requires care, and some have suggested that these instruments be considered single-use devices. ${ }^{31}$ Glass bead sterilizer is still a common method for chair-side sterilization of small dental hand instruments, especially endodontic files. Previous study showed that sterilization by the bead sterilizer can be achieved within few seconds. ${ }^{32}$ The common method of using bead sterilizer for sterilization time of few seconds is not effective and the sterilization time has to be at least $60 \mathrm{sec} .{ }^{33}$ Chemical sterilization may not be adequate sterilization methods for endodontic hand files and should not be relied on to provide completely sterile instruments. Only proper steam autoclaving reliably produces completely sterile instruments. Therefore, the need to emphasize on proper sterilization of endodontic instruments by manual cleaning, ulrasonics cleaners and washer disinfector and autoclaving is important to control the bio burden because dental instruments that are difficult to clean are frequently contaminated with tissue debris after routine reprocessing and cannot be excluded as a potential transmission risk for infectious agents, including prions. ${ }^{34,35}$
Eighty- three percent of the GDPs thought they need further training in endodontics among which, $50.9 \%$ preferred continued education courses with hand-on program. Post-graduate program was preferred by $42 \%$, part-time structured program by $24 \%$ and continued education courses (lectures) by $11 \%$.

Although only the GDPs willing to volunteer for the study are included in the study and the number of participants may not truly represent the GDPs of Kathmandu, it providescollective information on endodontic practice among GDPs of Kathmandu valley. In the future, there is a need of investigating the endodontic knowledge, attitude and reasons for not following the international endodontic guidelines and make future policies so as to overcome the difficulties in different fields in endodontics.

\section{CONCLUSION}

Within the limitation of the study, it can be concluded that most of the GDPs of Kathmandu are not following the acknowledged international academic standards. There is a need for conduction of continued dental education programs in the field of endodontics to encourage and implement the new technologies in their daily practice.

\section{REFERENCES}

1. Jenkins SM, Hayes SJ, Dummer PMH. A study of endodontic treatment carried out in dental practice within the UK. IntEndod J.2001;34(1):16-22.

2. Chan AWK, Low DCY, Cheung GSP, Ng RPY. A questionnaire survey of endodontic practice profile among dentists in Hong Kong. Hong Kong Dent J. 2006;3(2):81-87 
Journal of College of Medical Sciences-Nepal, 2013, Vol-9, No-4,

3. Al-Omari WM. Survey of attitudes, materials and methods employed in endodontic treatment by general dental practitioners in North Jordan.BMC Oral Health. 2004;4(1):1

4. Slaus G, Bottenberg P. A survey of endodontic practice amongst Flemish dentists. IntEndod J. 2002;35:759-767.

5. Vadhera N, Makkar S, Kumar R et al. Practice profile among endodontists in India: A nationwide questionnaire survey. Ind $\mathrm{J}$ Oral Sci. 2012;3(2):90-93.

6. Ahmed MF, Elseed Al, lbrahim YE: Root canal treatment in general practice in Sudan. IntEndod J. 2000;33:316-319.

7. Thayer-Hart, N.Survey Fundamentals: A Guide to Designing and Implementing Surveys; Office of Quality Improvement, University of Wisconsin Survey Center: Madison, WI, USA, 2010.

8. Ahmad IA.Rubber dam usage for endodontic treatment: a review. IntEndod J.2009;42(11):963-72.

9. Mohammadi Z, Farhad A, Tabrizizadeh M.One-visit versus multiple-visit endodontic therapy—a review.Int Dent J. 2006;56(5):28993.

10. Sathorn C, Parashos P, Messer HH. Effectiveness of single- versus multiple-visit endodontic treatment of teeth with apical periodontitis: a systematic review and metaanalysis. IntEndod J. 2005;38:347-355.

11. Spangberg LS. Evidence-based endodontics: the one-visit treatment idea. Oral Surg Oral Med Oral Pathol Oral RadiolEndod. 2001;91(6):617-8.

12. Figini L, Lodi G, Gorni Fet al. Single versus multiple visits for endodontic treatment of permanent teeth: a Cochrane systematic review. J Endod. 2008;34(9):1041-7.
13. Kawashima N, Wadachi R, Suda Het al.Root canal medicaments. Int Dent J.2009;59(1):511.

14. Ingle JI, Walton RE, Malamed SF et al. Preparation for endodontic treatment. Endodontics. $5^{\text {th }}$ Ed. Hamilton. BC Decker Inc., 2002:358.

15. Patel S, Mannocci F, Shemesh Het al. Radiographs and CBCT-time for a reassessment? IntEndod J.2011; 44(10):887-8.

16. Pineda F, Kuttler Y. Mesiodistal and Buccolingualroentgenographic investigation of 7,275 root canals. Oral Surg Oral Med Oral Path. 1972;33:101-10.

17. SmadiL. Comparison between two methods of working length determination and its effect on radiographic extent of root canal filling: a clinical study.BMC Oral Health. 2006;6:4.

18. Sharma CMC, Arora MGV. Determination of Working Length of Root Canal. MJAFI. 2010;66(3):231-4

19. Pasqualini D, Bianchi CC, Paolino DSet al. Computed micro-tomographic evaluation of glide path with nickel-titanium rotary PathFile in maxillary first molars curved canals.J Endod. 2012;38(3):389-93.

20. Tortini D, Colombo M, Gagliani M. Apical crown technique to model canal roots. A review of the literature. Minerva Stomatol. 2007;56(9):445-59.

21. Peters OA, Schonenberger K, Laib A. Effects of four Ni-Ti preparation techniques on root canal geometry assessed by micro computed tomography. IntEndod J. 2001;34:221-30.

22. Zehnder M. Root Canal Irrigants. J Endod. 2006;32(5):389-98.

23. Shrestha R, Shrestha N, Shrestha Set al.Irrigation practice among general dental practitioners of Nepal. JNDA. 2013;13(1):15-21. 
An Endodontic Practice Profile Amongst General Dental Practitioners.

24. Haapasalo M, Shen Y, Qian W et al. Irrigation in Endodontics. Dent Clin N Am. 2010;54:291312

25. Peng L, Ye L, Tan H, et al. Outcome of root canal obturation by warm gutta-percha versus cold lateral condensation: a meta-analysis. $J$ Endod.2007;33(2):106-9.

26. Johnson WT, Gutmann JL. Obturation of the cleaned and shaped root canal system. In: Cohen S, Hargreaves KM, eds. Pathways of the pulp. 9th ed. St Louis: Mosby, Inc., 2006:35899.

27. Suzuki P, Souza Vd, Holland Ret al.Tissue reaction to Endométhasone sealer in root canal fillings short of or beyond the apical foramen. J Appl Oral Sci. 2011;19(5):511-6.

28. Forman GH, Ord RA. Allergic endodontic angio-oedema in response to periapical endomethasone.Br Dent J. 1986;24;(10):34850.

29. Braun JJ, Zana H, Purohit A, et al. Anaphylactic reactions to formaldehyde in root canal sealant after endodontic treatment: four cases of anaphylactic shock and three of generalized urticaria.Allergy. 2003;58(11):1210-5.

30. Shrestha D, Wei X, Wu WC et al.Resilon: a methacrylate-resin based obturation system. $J$ Dent Sci 2010;5(2):47"52.

31. Teixeira FB, Teixeira EC, Thompson JY et al. Fractureresistance of roots endodontically treated with a new resin filling material. $J A m$ Dent Assoc 2004;135:646"52.

32. Schwartz RS. Adhesive dentistry and endodontics. Part 2: Bonding in the root canal system-The promise and the problems: a review. J Endod 2006;32:1125-1134

33. Mohammadi Z, Abbott PV. On the local applications of antibiotics and antibiotic-based agents in endodontics and dental traumatology. IntEndod J. 2009;42(7):555-67.

34. Morrison A, Conrod S. Dental burs and endodontic files: are routine sterilization procedures effective? J Can Dent Assoc. 2009;75(1):39.

35. Canalda-Sahli C, Pumarola-Suñe J, EspiasGomez A et al. Efficacy of the glass bead sterilizer on endodontic instruments. $\mathrm{Rev} \mathrm{Fr}$ Endod. 1989;8(4):29-34.

36. Zadik Y, Peretz A. The effectiveness of glass bead sterilizer in the dental practice. RefuatHapehVehashinayim.2008;25(2):36-9, 75.

37. Hurtt CA, Rossman LE. The sterilization of endodontic hand files.J Endod. 1996;22(6):321-322.

38. Walker JT, Dickinson J, Sutton JMet al. Cleanability of dental instrumentsimplications of residual protein and risks from Creutzfeldt-Jakob disease. $B r$ Dent $J$. 2007;203(7):395-401. 